\title{
FORMULATION OF CHLORPROMAZINE BIO-NANO GEL USING PRUNUS AMYGDALUS BIO-RETARDANT FOR BRAIN TARGETING VIA NASAL ROUTE.
}

\author{
N.V. Satheesh Madhav, Deepika Raina \\ Novel drug delivery Research Lab Dehradun Institute of Technology University, Makkawala, P.O Bhagwantpura- \\ 248009, Dehradun, Uttrakhand, India
}

\begin{abstract}
CNS disorders and diseases demand effectual delivery of drugs into the brain. However, transporting drugs to the brain still remains a difficult task due to the occurrence of a clenched blood-brain barrier (BBB). Many therapeutic agents may have been restrained because sufficient drug levels in the brain cannot be achieved via the systemic circulation. A non-invasive therapy would be desirable to explore alternative route of delivery to transport drugs to the brain. One of the alternative methods for brain delivery is intranasal administration. Our research work aimed to formulate bio-nano particles loaded with chlorpromazine using a novel bio-retardant from Prunus amygdalus. The bio-polymer was isolated from novel method by addition of non aqueous solvent. Five formulations were prepared using Chlorpromazine, and Prunus amygdalus as bio-polymer, and five from the synthetic polymer Pullulan gum varying concentration of bio-polymer and synthetic polymer. The nano-particles were prepared by solvent evaporation method and were evaluated for drug content entrapment efficacy in-vitro drug release in-vivo studies and stability studies.on the basis of in-vitro drug release in-vivo, pharmacokinetic data and muco adhesivity FA10(1:9) displayed the best results whose $R^{2}$ value was 0.9305 and hence selected as the best formulation depicted by bits software. Delivery of API molecule to the brain for the management of depressive disorder is significant, minimizes the ADR and side effects of therapeutic molecule and offer good patient compliance through this novelistic approach.
\end{abstract}

Keywords: Prunus amygdalus, Brain targeting, Chlorpromazine.

\section{INTRODUCTION}

Hundreds of millions of people worldwide are affected by neurological disorders. Schizophrenialis a severe mental disorder which affects more than 21 million people worldwide. Characterized by profound disruptions in thinking, affecting language, perception, and the sense of self. It often includes psychotic experiences, such as hearing voices or delusions. It can impair functioning through the loss of an acquired capability to earn a livelihood, or the disruption of studies. Over 800000 people die by suicide every year - that's one person every 40 seconds. Yet these deaths are preventable (1). 10 percent to 13 percent killing themselves and approximately $40 \%$ attempting suicide at least once (and as much as $60 \%$ of males attempting suicide). The extreme depression and psychoses that can result due to lack of treatment are the usual causes (2).

Intranasal delivery does not involve any change

*Corresponding author:

Email: Satheesh_madhav@yahoo.com

http://dx.doi.org/00.12345/IJTA 31 5-9

ISSN 2320-138X of the therapeutic agents and does not require that drugs be coupled with any carrier like in case of drug delivery across the BBB. This route, involves the olfactory or trigeminal neural systems. They are the only externally exposed portions of the CNS and therefore represent the most direct method of noninvasive entry into the brain. However, the quantities of drug administered nasally has been shown to be transported directly from nose-to-brain is very low, normally less than $0.1 \%$. The most obvious possibility is that there direct transport to the brain along the olfactory nerve $(3,4)$.

\subsection{Mechanistic Drug Delivery Approach:}

The olfactory epithelium is a gateway for substances entering the CNS and the peripheral circulation. The neural connections between the nasal mucosa and the brain provide a unique pathway for the non-invasive delivery of therapeutic agents to the CNS (5-7). The olfactory neural pathway provides both an intra-neuronal and extraneuronal pathway into the brain (8-10). The intraneuronal pathway involves axonal transport and requires hours to days for drugs to reach different brain regions. While the extra-neuronal pathway probably relies on bulk flow transport through perineural channels, which deliver drugs directly to 


\section{Graphical Abstract}

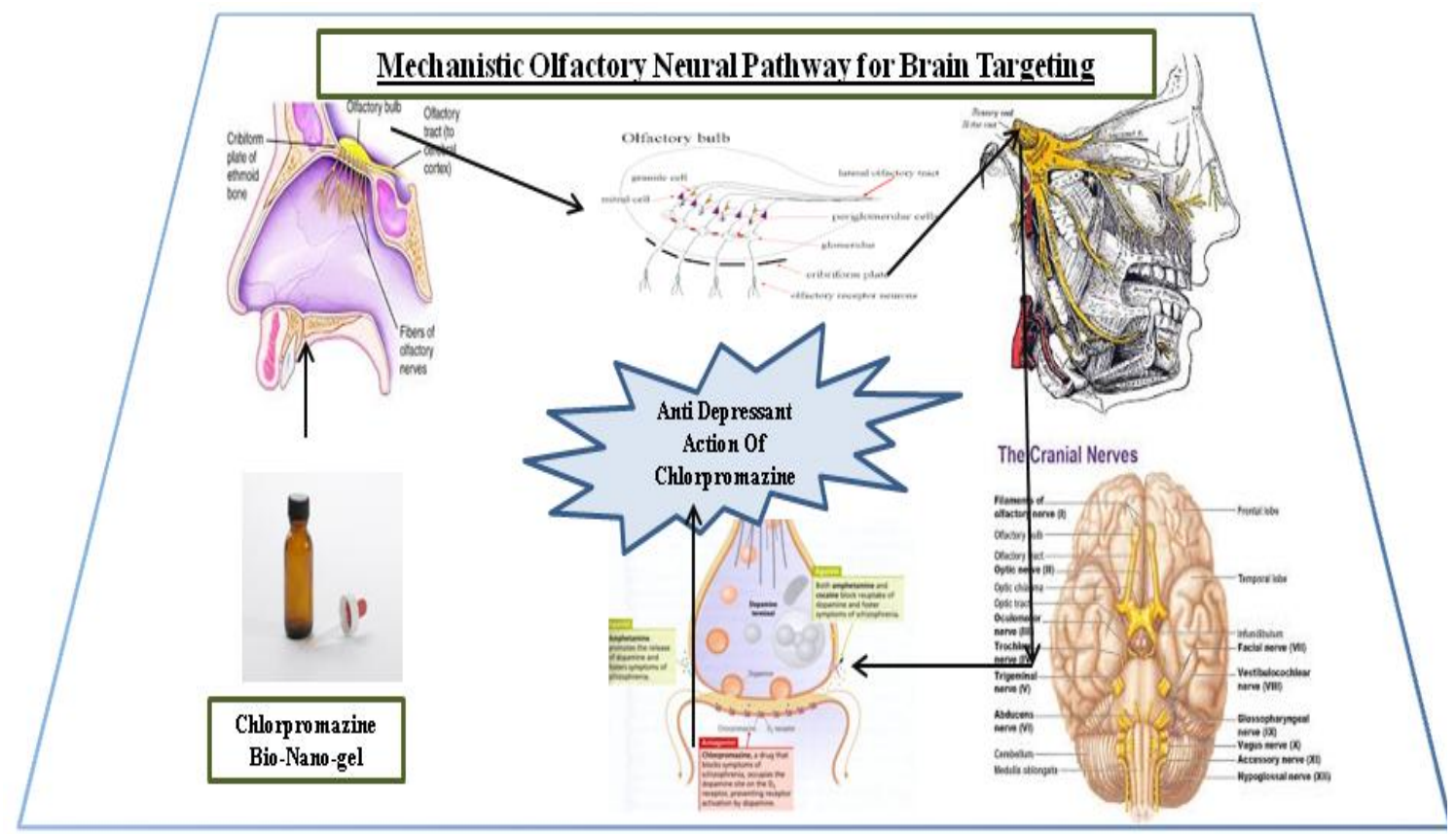

the brain parenchymal tissue and/or CSF. The extraneuronal pathway allows therapeutic agents to reach the CNS within minutes ${ }^{[11-14]}$. The Prunus amygdalus contains about $26 \%$ carbohydrates (12\% dietary fiber, $6.3 \%$ sugars, $0.7 \%$ starch and the rest miscellaneous carbohydrates),

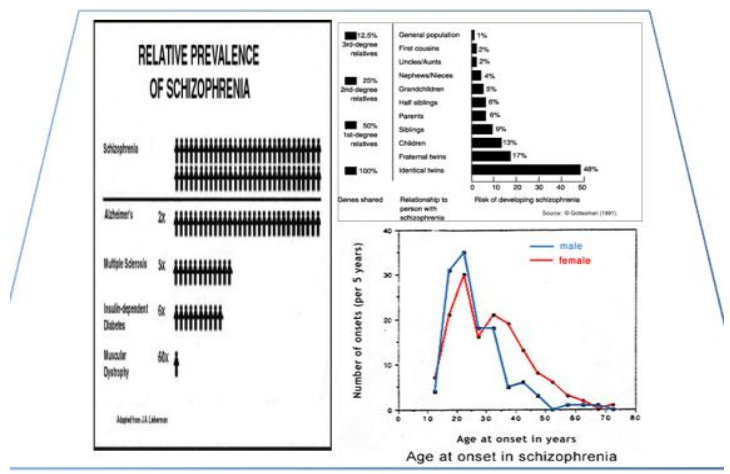

Fig. 1

\section{MATERIALS AND METHODS}

2.1 Isolation of bio-material from the seeds of Prunus amygdalus

250 grams of Prunus amygdalus kernels were soaked in distilled water for $24 \mathrm{Hrs}$. The outer cover was removed, and was grinded into a paste. $300 \mathrm{ml}$ water was added to the paste and it was filtered through a muslin cloth. The filtrate was centrifuged at $3000 \mathrm{rpm}$ to remove the residual matter. The optimization was performed by taking $2 \mathrm{ml}$ of the filtrate and $2 \mathrm{ml}$ of various non aqueous solvents The maximum yield was obtained with propanone, hence used as the solvent for extraction. The remaining filtrate was added with equal quantity of propanone and kept in refrigerator for $24 \mathrm{hrs}$. The settled biomaterial was separated by centrifugation at 4000rpm for 10 mins. The bio-materials was dried in vacuum desiccators for $48 \mathrm{hrs}$ The process of biomaterial extraction was repeated 6 times \& practical yield was calculated. The \% yield for $P$. amygdalus was found to be $10.2 \pm 2.33 \%$ with a color changing point of $275^{\circ} \mathrm{C} \pm 5^{\circ} \mathrm{C}$. The bio-materials were purified and no presence of chlorides, sulphates and starch was observed

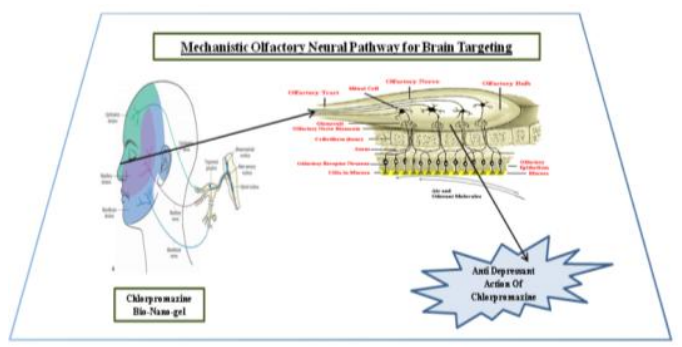

Fig. 1 


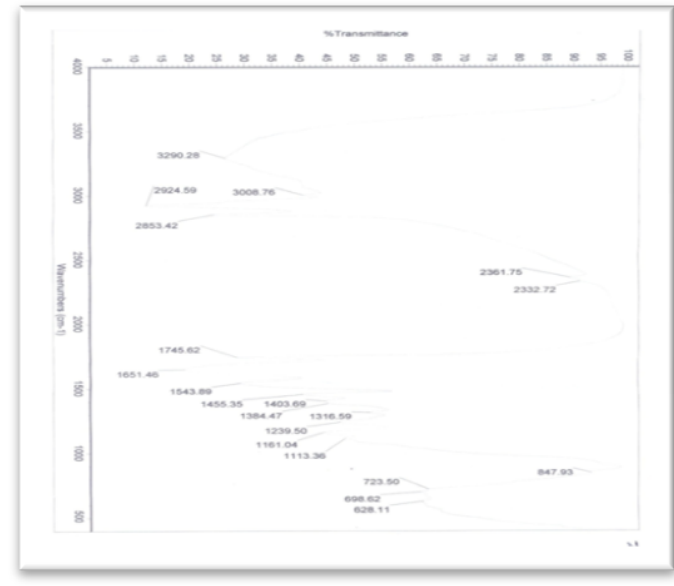

Fig 2. IR Spectra of Prunus amygdalus

2.2 Physico-chemical characterization of the biopolymer:

The isolated bio-material was white in colour, odourless, characteristic taste, partially soluble in water, colour changing point of $270-275^{\circ} \mathrm{C}$. It had a viscosity of $1.54 \mathrm{cps}$, carbohydrates were absent while proteins were present.

The IR spectra revealed the presence of tertiary $\left(1078.13 \mathrm{~cm}^{-1}\right)$, secondary alcohols,(1151.13 $\left.\mathrm{cm}^{-1}\right)$ aromatic rings $\left(1598.88 \mathrm{~cm}^{-1}\right)$ and the presence of alkanes, alkenes(2925.81 $\left.\mathrm{cm}^{-1}\right)$ and nitro compounds along with ketones $\left(1678.5 \mathrm{~cm}^{-1}\right)$ (fig. no2). These groups like the ketonic groups, nitro groups indicate the mucoadhesive activity of the biopolymer as these groups are observed in the mucoadhesive polymers like HPMC, polycarbophil. The SEM analysis pf the bio-polymer revealed that it has a smooth surfacewith no rough edges. It shows the smooth, amorphous nature of the biopolymer.the bio-polymer showed a morphological structure similar to the polymers and hence it confirms the polymeric nature of the bio-polymer (Fig 3).

\section{Table1: Characterization}

\begin{tabular}{|c|c|c|}
\hline 1. & Color & White \\
\hline 2. & Odor & odorless \\
\hline 3. & Taste & characteristic \\
\hline 4. & Solubility & $\begin{array}{l}\text { Partially soluble } \\
\text { in water }\end{array}$ \\
\hline 5. & Melting point & $270-275$ \\
\hline 6. & Proteins & Present \\
\hline 7. & Carbohydrates & Absent \\
\hline
\end{tabular}

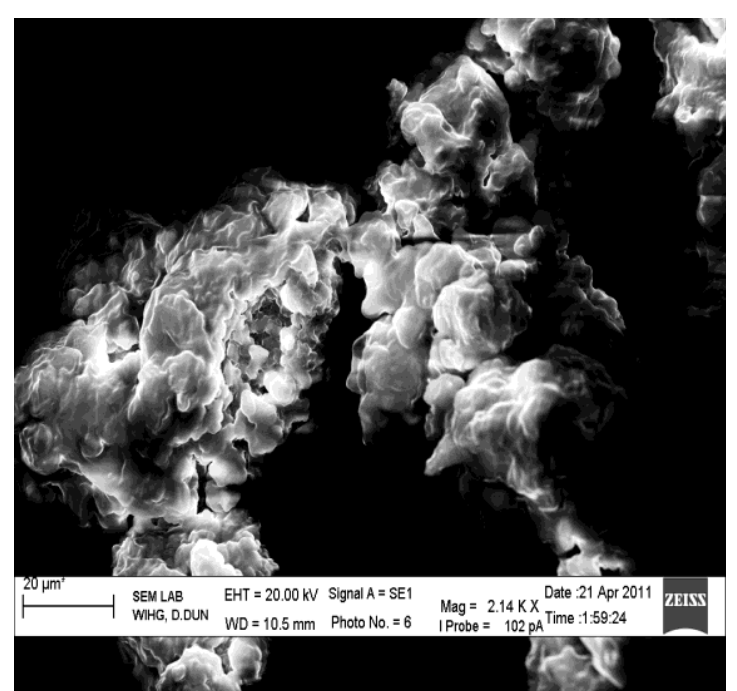

Fig3. SEM of Prunus amygdalus

2.3 screening of the isolated bio-polymers for mucoretentivity:

The isolated bio-polymers were screened for mucoadhesivity. The results revealed excellent mucoretention ability and filmability. The biopolymeric solutions had very good mucoadhesivity in a concentration ranging $2 \%-6 \%$.

\subsection{Drug interaction study:}

The drug interaction study revealed that there was no interaction between the drug and the excipients including the bio-polymers. This was proved by the result of the thin layer chromatography in which no change was seen in the RF value in the TLC method. Also there was no change in the $\lambda$ max. Value which was observed to be $258 \mathrm{~nm}$ prior to the test and after the test it was $258 \mathrm{~nm}$ hence confirming that there was no interaction between the drug and excipients. No observable signs of drug interaction were seen. It was conclude that none of the excipients had a detrimental effect on the drug and could be safely used for the formulation of the bio-films.

\subsection{Acute toxicity studies:}

The results of the acute toxicity studies revealed safety profile. They did not show any signs of toxicity, change in body weight, changes in the skin, corneal reflex, respiratory rate, autonomic symptoms, salivation, diarrhea, lethargy, sleep, behavioural patterns, and convulsions. The test group was comparable to the control group of 
animals. Hence it was conclude that the isolated biopolymers was safe and non-toxiic.

2.6 Formulation of CPZ bio-nanoparticles loaded with Prunus amygdalus biopolymer

Table2: Formulation Table

\begin{tabular}{|c|c|c|c|c|c|}
\hline Formulations & $\begin{array}{l}\text { FA1 } \\
(1: 1)\end{array}$ & $\begin{array}{l}\text { FA4 } \\
(1: 5)\end{array}$ & $\begin{array}{l}\text { FA5 } \\
(1: 2)\end{array}$ & $\begin{array}{l}\text { FA6 } \\
(1: 3)\end{array}$ & $\begin{array}{l}\text { FA10 } \\
(1: 9)\end{array}$ \\
\hline $\begin{array}{l}\text { Drug: polymer } \\
\text { ratio }\end{array}$ & $1: 1$ & $1: 2$ & $1: 3$ & $1: 5$ & $1: 9$ \\
\hline $\begin{array}{l}\text { chlorproma- } \\
\text { zine (mg) }\end{array}$ & 10 & 10 & 10 & 10 & 10 \\
\hline $\begin{array}{l}\text { Prunus } \\
\text { amygdalus Bio- } \\
\text { polymer (mg) }\end{array}$ & 10 & 20 & 30 & 50 & 90 \\
\hline Glycerin $\mu l$ & 60 & 60 & 60 & 60 & 60 \\
\hline $\begin{array}{l}\text { Distilled } \\
\text { water(ml) }\end{array}$ & 5 & 5 & 5 & 5 & 5 \\
\hline $\begin{array}{l}\text { Buffer }(\mathrm{ml}) \mathrm{pH} \\
5.5\end{array}$ & 5 & 5 & 5 & 5 & 5 \\
\hline
\end{tabular}

2.7. Formulation of CPZ bio-nanoparticles loaded with phululan gum (pg):

Chlorpromazine bio-nanoparticles using standard polymers phululan gum were prepared by using "Novel method ".In this method the standard polymer was accurately weighed in different ratios and treated with glycerine $(0.24 \mathrm{gm})$, glycerine is used as a wetting agent, and then to this slurry distilled water $(5 \mathrm{ml})$ was transferred into mechanical stirrer. The drug $(10 \mathrm{mg})$ solution was prepared separately with methanol $(5 \mathrm{ml})$. The drug solution

Table3: Formulation Table:

\begin{tabular}{|c|c|c|c|c|c|}
\hline Formulations & $\begin{array}{l}\text { Fpg1 } \\
(1: 1)\end{array}$ & $\begin{array}{l}\text { Fpg4 } \\
(1: 5)\end{array}$ & $\begin{array}{l}\text { Fpg5 } \\
(1: 2)\end{array}$ & $\begin{array}{l}\text { Fpg6 } \\
(1: 3)\end{array}$ & $\begin{array}{l}\text { Fpg10 } \\
(1: 9)\end{array}$ \\
\hline $\begin{array}{l}\text { Drug:polymer } \\
\text { ratio }\end{array}$ & $1: 1$ & $1: 2$ & $1: 3$ & $1: 5$ & $1: 9$ \\
\hline $\begin{array}{l}\text { chlorproma- } \\
\text { zine (mg) }\end{array}$ & 10 & 10 & 10 & 10 & 10 \\
\hline $\begin{array}{l}\text { Pullulan gum } \\
\text { (mg) }\end{array}$ & 10 & 20 & 30 & 50 & 90 \\
\hline Glycerin ( $\mu$ l) & 60 & 60 & 60 & 60 & 60 \\
\hline $\begin{array}{l}\text { Distilled } \\
\text { water(ml) }\end{array}$ & 5 & 5 & 5 & 5 & 5 \\
\hline $\begin{array}{l}\text { Buffer (ml) pH } \\
5.5\end{array}$ & 5 & 5 & 5 & 5 & 5 \\
\hline
\end{tabular}

was added to the polymeric solution under stirring 4,500 RPM until the formation of nanoparticles for about half an $\mathrm{hr}$. The beaker containing the sample was subjected for 5 cycles of sonication for $3 \mathrm{~min}$. The sample was micro-centrifuged at 5000 RPM for $10 \mathrm{mins}$, and was dried at room temperature for $24 \mathrm{hrs}$.

\section{RESULTS}

The content uniformity of FA1-FA5 was found to be $90.7 \pm 0.1 \%-97.4 \pm 0.05 \%$.having $\mathrm{pH} 7-8$ out of ten formulations five were prepared by the almond biopolymer and five from the synthetic biopolymer FA10 (1:9) was found to be best formulation was whose $R^{2}$ value was 0.9305 and best fit model was Peppas and mechanism of release was Anomalous having $t_{50}$ of 266.93 hrs. The release kinetics was depicted by BITS software

\section{CONCLUSION}

People with the condition(Schizophrenia) have a 50 times higher risk of attempting suicide than the general population; the risk of suicide is very serious in people with schizophrenia. Suicide is the number one cause of premature death among people with schizophrenia, with an estimated 10 percent to 13 percent killing themselves and approximately $40 \%$ attempting suicide at least once (and as much as $60 \%$ of males attempting suicide

Nanoparticles (NPs) could be an exciting prospect for transnasal drug delivery as they have higher surface area to cover highly vascularised nasal absorptive area providing a greater concentration gradient. NPs are used as a sustained drug delivery system. NPs, interacts with mucus to prolong the residence time of drug carrier at the drug absorption sites and protected the entrapped drug from enzymatic degradation until they are absorbed. Therefore, the bioavailability of drug is improved. The research work ensured that bio-polymer is safe and effective and can be used in the preparation of bio-nanoparticles. The isolated biomaterial was used as a novel material for the formulation of the bionanoparticles loaded with Chlorpromazine. Standard polymers pullalan gum was also used for the preparation of the standard formulations. The bionanoparticles were prepared by "Modified NonSolvent Nano-precipitation Method". It can be concluded that the biopolymer can be used for the preparation of NPs for nose to brain delivery as Pharmacokinetic study reveals that significant amount of drug reaches to the brain when 
administered intranasally and same was confirmed by observation as calmness in experimental animal. Delivery of API molecule to the brain for the management of depressive disorder is significant, minimizes the ADR by decreasing the dose and side effects of therapeutic molecule and offer good patient compliance through this novelistic approach.

\section{REFERENCE}

1. World Health Organization. World Health Organization. 2016 [cited 5 December 2015]. http://www.who.int/en/

2. Schizophrenia.com. Schizophrenia Help \& News for Families, Sufferers. 2015 [cited 5 December 2015]. http://www.schizophrenia.com

3. van Laar T, Van der Geest R, Danhof M. Future delivery systems for apomorphine in patients with Parkinson's disease. Adv Neurol. 1999;80:535-44. PubMed PMID: 10410768.

4. Pavan B, Dalpiaz A, Ciliberti N, Biondi C, Manfredini S, Vertuani S. Progress in Drug Delivery to the Central Nervous System by the Prodrug Approach. Molecules. 2008 May 1;13(5):1035-65. http://dx.doi.org/10.3390/molecules13051035

5. Illum L. Transport of drugs from the nasal cavity to the central nervous system. European Journal of Pharmaceutical Sciences. 2000 Jul;11(1):1-18. http://dx.doi.org/10.1016/s0928-0987(00)00087-7

6. Mathison S, Nagilla R, Kompella UB. Nasal Route for Direct Delivery of Solutes to the Central Nervous System: Fact or Fiction? Journal of Drug Targeting. 1998 Jan;5(6):415-41. http://dx.doi.org/10.3109/10611869808997870

7. Thorne RG, Frey WH. Delivery of Neurotrophic Factors to the Central Nervous System. Clinical Pharmacokinetics. 2001;40(12):907-46. http://dx.doi.org/10.2165/00003088-200140120$\underline{00003}$

8. Thorne RG, Emory CR, Ala TA, Frey WH. Quantitative analysis of the olfactory pathway for drug delivery to the brain. Brain Research. 1995 Sep;692(1-2):278-82. http://dx.doi.org/10.1016/0006-8993(95)00637-6

9. Balin BJ, Broadwell RD, Salcman M, El-Kalliny M. Avenues for entry of peripherally administered protein to the central nervous system in mouse, rat, and squirrel monkey. J Comp Neurol. 1986 Sep $8 ; 251(2): 260-80$. http://dx.doi.org/10.1002/cne.902510209

10. Broadwell RD, Balin BJ. Endocytic and exocytic pathways of the neuronal secretory process and trans synaptic transfer of wheat germ agglutininhorseradish peroxidasein vivo. J Comp Neurol. 1985 Dec 22;242(4):632-50. http://dx.doi.org/10.1002/cne.902420410

11. Treatmentadvocacycenter.org. Treatment Advocacy Center. 2016 [cited 5 December 2015]. http://www.treatmentadvocacycenter.org/ 